\title{
NETWORKS OF INVENTORS IN THE CHEMICAL INDUSTRY
}

\author{
Myriam Mariani \\ MERIT, University of Maastricht, Maastricht \\ CUSTOM, University of Urbino, Urbino \\ mymarian@tin.it
}

January, 2000

\begin{abstract}
By using extremely detailed data on European chemical patents, this work focuses on the micro level of research networks. It examines the networks of inventors for the development of innovations. It studies whether the firm or the geographical proximity among inventors influences the probability that inventors collaborate, and the attributes of the outcome patents. The results suggest that the firm, and in particular the large multinational company is a good coordination mechanism for fostering such collaborations. As for geographical proximity, it matters when the inventors are localised in a technological cluster.
\end{abstract}

\section{Introduction}

Research networks are common practice of today's scientific and technological work. Based on co-authored journal articles, quite a few studies have explored the characteristics, the motives and the effects of research collaborations among scientists. (See, among others, de Solla Price, 1966; Merton, 1973; Melin, 1999). Our work examines R\&D collaborations that lead to technological outcomes. It looks at the networks of inventors that produce patented innovations in the chemical industry. It describes the characteristics of these networks, and investigates the role of the geographical proximity compared to the affiliation to the same organisation for fostering such collaborations.

This paper also contributes to the literature on knowledge spillovers. Some authors argue that technological spillovers and knowledge exchange are more pronounced when the agents are geographically close (Jaffe, 1986; Jaffe, Trajtenberg and Henderson, 1993; Audrestch and Feldman, 1996). These studies are based on the assumption that spillovers are unintended knowledge flows, and that, as such, they are merely "in the air". Some recent contributions, however, argue that geographical proximity does not stimulate productivity growth per sé, and that spillovers arise from specific actions of economic agents. (Zucker, Darby and 
Armstrong,1998; Lamoreaux and Sokoloff,1997 and 1998). To benefit from spillovers firms have to set up "formal" collaborations with external agents. By looking at the formation of networks of inventors for the development of innovations, our research describes a formal mechanism through which knowledge is exchanged as opposed to undeliberate spillovers.

In so doing, this chapter uses a micro level approach. It refers to networks as those relationships that inventors in the chemical sector develop among them in order to produce commercially valuable inventions. The ties among the agents are knowledge transactions with the aim of gaining knowledge spillovers. The empirical investigation is based on a very detailed and systematic analysis of patent data drawn from the EPO (European Patent Office) and other data sources. (See detailed information in the Appendix.) The geographical unit of analysis is the European region according to the NUTS classification (Nomenclature des Unités Territoriales Statistiques). This classification subdivides the European Union in 77 groups of regions (NUTS1), 206 regions (NUTS2) and 1,031 provinces (NUTS3). One of the novelties of this work is that it uses data at the most disaggregated NUTS3 level.

We begin by introducing some of the relevant literature on technological spillovers and research collaboration, and by presenting the objective of the analysis (Section 2). Section 3 describes some general trends in the networks of assignees and inventors in the chemical sector. Section 4 compares the effect of the firm and the technological proximity over the collaborations. Section 5 checks for multiple correlations by means of Poisson and Negative Binomial regressions. Section 6 discusses the results. The final section concludes.

\section{Networks of inventors as a formal mechanism to absorb technological spillovers.}

The literature on regional clustering shows that there are different motives for the clustering of innovative activity. Like in production, economies of scale stimulate firms to locate a certain activity in one geographical area. In addition to this, innovative activities tend to cluster geographically because they benefit from localised technological spillovers (e.g. Jaffe, 1986, Jaffe, Trajtenberg and Henderson, 1993; Coe and Helpman, 1995; Audrestch and Feldman, 1996). Although these spillovers are thought to be an important means for generating economic benefits from the investment in technology, the literature gives only limited explanation on the mechanisms that give rise to them. Most authors treat spillovers as 
unintended knowledge flows, thanks to which the investment undertaken by one firm or person generates externalities that benefit many others.

Some recent studies, however, show that spillovers do not occur unintentionally. The rise of externalities depends on specific complementary actions of economic agents. Zucker, Darby and Armstrong (1998) show that in California the geographical proximity of biotechnology companies with academic scientists does not stimulate per sé the economic performance of the companies. Only when these firms have "formal" relationships with the scientists in the academy (e.g. joint papers, presence of scientists in the Board of Directors), these "formalised" spillovers have a positive impact on their growth. The study on the glass industry by Lamoreaux and Sokoloff (1997 and 1998) reaches similar conclusions. They show that in the late nineteenth and early twentieth centuries, innovative activity in the American glass industry proceeded most intensively in areas where markets for technology had developed most fully. In other words, inventors were more fertile where information flows were organised by localised networks of institutions that mobilised information about technological opportunities, and mediated relations among the inventors and the users of the innovations. Freeman (1991) also demonstrates the vital importance of formal and informal networks of information and collaboration for the development of successful innovations. As far as the formal networks are concerned, he examines the growth of different forms of inter-firm networking over time (i.e. joint ventures, joint $R \& D$ agreements, licensing, etc.). He also emphasised the regional, national and international level of these collaborations.

Our investigation examines another "formal mechanism" for the exchange of knowledge. This is the network of inventors that take part in the development of a patent. These are networks of agents that collaborate, and exchange knowledge for the production of innovations, as opposed to undeliberate spillovers. In other words, these networks are a formalised and measurable mechanism through which knowledge spillovers take place.

Related to the issue of collaborations as indicators of knowledge exchange, several contributions have explored the motives and the benefits that arise when scientists collaborate. (See, among others, de Solla Price 1966; Merton 1973; Narin and Withlow, 1990). In a recent paper, Melin (1999), argues that co-authorship is a "a more substantial indicator [of cooperative efforts] than just communication in one way or another. There has to be a 
distinction between fruitful chats over coffee and systematised collaboration with publications as one result". By using the results of a questionnaire and the interviews to 195 authors of coauthored articles, Melin found that there are several reasons that lead scientists to collaborate such as the possibility to communicate ideas, to work on the basis of common research interests, to get access to complementary skills, and to share data and equipment. The benefits generated from the collaboration have to do with the higher quality of the output compared to the expected results of single scientists' research.

Most of these studies on R\&D collaborations focus on scientific outputs - i.e. co-authored journal articles - as indicators of research networks. From a different perspective, our paper explores research collaborations that lead to more technological outcomes - i.e. patented inventions. The question that the paper addresses is: How does geographical proximity matter for establishing collaborations compared to the affiliation to the same firm? Or, in other words, are geographical proximity and the organisation of the firm two alternative "coordination modes" for these "formalised" knowledge spillovers to take place? To answer this question the paper explores whether regional characteristics and firm's characteristics influence the probability of collaborating, and whether they affect the characteristics of the innovations produced. Our two propositions are:

- The firm is an efficient mechanism for organising knowledge spillovers. We expect that the effectiveness of the organisation in fostering the collaborations is greater than the benefits arising from geographical proximity. This is because the unique competencies, the internal communication systems, and the routines that the firm develops over time help reduce the cost of coordinating different parts of the organisation and different individuals - in our case, researchers involved in a common R\&D project. Hence, patents developed by the firm are expected to have a larger number of inventors and to be more complex compared to the average. This is even more so for large multinational companies that can coordinate a larger number of researchers localised in different parts of the organisation by using their internal networking structure, and their underlying tacit competencies.

- Geographical proximity is also an efficient means for fostering collaboration among inventors. However, some qualifications are needed. Geographical proximity is a good coordination mechanism when the inventors are localised in a technology intensive region - 
i.e. in a technological cluster. Moreover, the technological cluster is a more important coordination mode for small firms compared to large internationalised companies. This is because geographical proximity in a technology-intensive region might compensate the lack of competencies and organisational capabilities of smaller organisations. Therefore, we expect companies to produce more complex patents in a technological cluster than in a non-cluster area. Moreover, small firms are expected to develop a higher share of patents in the cluster compared to large multinationals.

To test these propositions we use information contained in about 200,000 chemical patents applied or granted at the European Patent Office during 1986-1997. By using the information contained in the patent document we define three patent characteristics:

1. Co-localised and De-localised patents (hereafter CL or DL). The address of the inventors listed in each patent is assumed to be the actual location of the innovative activity, at least for that inventor. At the country level, a patent is termed CL if all the inventors are localised in the same nation. If one or more inventors have a different nationality, the patent is defined as DL. At the regional level, a patent is CL if all the inventors are localised in the same NUTS3 region. By contrast, if at least one of them is localised in a different NUTS3 region, the patent is DL. We consider the inventors that produce a DL patent as inventors affiliated to the same company. ${ }^{1}$ The logic behind this assumption is the following. Suppose that a patent is CL. A CL patent can be thought of as the outcome of the geographical proximity among the inventors: either inventors belonging to the same laboratory - and hence to the same firm - or inventors belonging to different firms, and located in the same region - i.e. the cluster. Hence, a CL patent can be the outcome of the coordination played by both the firm and the cluster. No distinction can be made by using the information that we have. By contrast, a DL patent is the result of the collaboration among inventors localised in different places. This means that the production of a DL patent is not the outcome of the geographical proximity among inventors - i.e. the cluster or the laboratory. Since almost all DL patents are assigned to single assignees, one can assume that the inventors of a DL patent belong to the same firm. In this

\footnotetext{
${ }^{1}$ This assumption is strengthened by the fact that, when we select a random sample of 560 patents out of the universe of chemical patents (see Section 5), almost all DL patents are assigned to single assignees - where the assignee is the person, the institution or the firm who has the right to exploit a patent. Precisely, only 6 patents out of 30 patents with multiple assignees in the sample are DL. The assignee is the person, the institution or the firm who has the right to exploit a patent. Only 6 patents out of 30 patents with multiple assignees are DL.
} 
sense, the invention is the outcome of the organisation of the firm as a means to reduce the cost of coordinating research networks.

2. Interdisciplinary of patents. The interdisciplinarity of a patent is proxied by the number of supplementary classes in which the patent has been classified by the experts of the EPO. Each patent is classified in one main obligatory technological class according to the International Patent Classification (IPC). Apart from the principal IPC class, the patent officers can assign other supplementary IPC classes, if they believe that the patent falls into other technological classes as well. The higher is the number of these supplementary classes, the more the patent is interdisciplinary.

3. Breadth of the network. The breadth of the network of inventors is proxied by the number of inventors listed in the patents. We use the interdisciplinarity of a patent and the breadth of the network that developed the patent as indicators of the "quality" of the collaboration. Intuitively, a higher coordination is needed when more interdisciplinary patents are developed, and when a larger number of inventors are involved.

\section{National and international networks of assignees and inventors.}

This part of the analysis uses the whole population of 201,531 chemical patents assigned or granted by the European Patent Office in 1986-1997. (See the Appendix for a detailed description of the data used in this paper). A patent is a temporary monopoly on a newly invented device awarded to whom (the assignee) will use it for commercial purposes. ${ }^{2}$ The front page of a patent contains detailed information about the invention, the inventor, and the assignee. Before looking specifically at the characteristics of the networks of inventors, we explore some features of the data.

We first examine the networks of assignees that collaborate to develop an innovation. If a patent lists more than one assignee, presumably the innovation has been developed by using different firms' inputs and competencies. Interestingly, however, 93.1\% of all patents have only one assignee vs. $7.9 \%$ patents with two or more assignees (multiple assignees). In other words, co-patenting is not common, at least in chemicals. This does not mean that firms do

\footnotetext{
${ }^{2}$ See Griliches (1990) and Scherer (1983) for the use of patents as a proxy for innovative activity.
} 
not collaborate in order to undertake innovation projects. Nonetheless, it is surprising that a natural innovation output like patents (especially in chemicals) does not show a significant degree of inter-firm cooperation and networking. ${ }^{3}$

Some deeper inspection in the multiple assignee patents show that there are differences in copatenting according to technological classes and countries of origin of the assignees. Thus, in the case of glass and fertilisers the percentage of patents assigned to multiple institutions is about $9 \%$. In the case of biotechnological innovations, the percentage of patents produced by multiple assignees is 19\%. Moreover, firms from countries like Belgium, Great Britain, Ireland, the Netherlands are more open to collaborating with other firms and institutions for the development of a joint-patent. Thirteen percent of patents assigned to Belgium, $21 \%$ of patents in Ireland, $23 \%$ of those assigned to Great Britain, and $28 \%$ of patents in the Netherlands are developed by multiple assignees. Another interesting - not surprising feature of the nature of co-patenting is that there is a marked tendency for choosing partners of the same nationality. Overall, $63.6 \%$ of patents with multiple assignees involve partners from the same country, while $36.4 \%$ involve cross-border relationships.

The pattern in co-patenting is in sharp contrast with the trends about the number of inventors. Only the $25.4 \%$ of all chemical patents are developed by single inventors. The rest $(74.6 \%)$ are done by two or more inventors. Hence, while there are few patents with multiple assignees, there is a great deal of collaboration among individuals. Again, however, these networks are mostly national. Overall, $91.6 \%$ of the patents developed by multiple inventors $(150,261$ patents) are among individuals from the same country. Only $8.4 \%$ of patents with multiple inventors involve international linkages.

It is also interesting that the number of inventors in a patent increases as the patents become more DL at the country level. The mean number of inventors is 4 in DL patents. It is 2.7 in CL patents. Also the mean number of supplementary classes of DL patents is slightly higher than that of CL patents ( 2 and 1.7 supplementary classes respectively). This might be due to the fact that, as the complexity of an R\&D project increases, also the demand for more differentiated and specialised competencies increases. In this case, the probability that the inventors are localised in the same country declines.

\footnotetext{
${ }^{3}$ Many studies show that there is a great amount of inter-firm collaboration in R\&D (see, for example,
} 
This is confirmed by the fact that the number of inventors increases with the level of interdisciplinary of the patent. The average number of inventors increases steadily from 2.5 in patents with no supplementary classes to 4.7 in patents with 12 supplementary classes. This is clearly associated with the fact that more complex projects require competencies of various types. In this case many inventors might be needed to pursue a highly interdisciplinary innovation.

We now turn to the question of whether the characteristics of the firm that produced the patent or the characteristics of the region in which the inventors are located affect the collaborations, and the features of the resulting innovations. Specifically, we investigate whether inventors belonging to large multinational firms or located in a technological cluster have a higher probability to collaborate, to produce co-localised $v s$. de-localised patents, and to develop larger networks for more interdisciplinary innovations. Put differently, this is one way to ask whether the firm or the cluster is a better coordination mode for promoting the collaboration among inventors.

\section{The network of inventors analysis.}

This part of the paper is based on a random sample of 560 innovations drawn from the whole set of 201,531 chemical patents. ${ }^{4}$ We checked several features of this sample, and - as we shall see from the analysis below - it appears to be fairly representative of the whole population. Of these 560 patents, 530 are assigned to single assignees. Only 30 patents are assigned to multiple assignees (up to 3 assignees). This is consistent with the percentage of multiple assignees calculated for the whole set of chemical patents. The analysis below is based on the first assignee. Their composition is as follows: 20 are Public institutions, excluding universities; 3 are universities; 23 are individual inventors (i.e. assignees who do not belong to any firm); 290 are large firms listed in Fortune 500 (1995), Who Owns Whom (1995) and Compustat (1995). We will refer to these 290 firms as the "Fortune 500" firms. The remaining 224 firms are not listed in Fortune 500 (1995), Who Owns Whom (1995) and Compustat (1995). We will term these firms as the "other" firms.

Freeman, 1991; Hagedoorn and Schakenraad, 1990). 
As far as the number of inventors is concerned, 146 patents (26.1\%) are developed by single inventors. The remaining $73.9 \%$ is invented by multiple inventors. To check whether this sample is representative of the whole population, we also computed the distribution of patents by number of inventors and degree of interdisciplinarity. Consistently with the results drawn for the whole set of chemical patents, the data show that the higher is the number of inventors that take part in an innovation, the higher is the probability of a patent being interdisciplinary. The average number of inventors is 2.3 for patents with no supplementary classes. It increases to 4.5 in patents with 12 supplementary classes.

\subsection{The "networking" firm and the networks of inventors.}

To test the proposition on whether the firm is an better mechanism for fostering research collaborations compared to the geographical proximity among inventors, we begin by computing the share of DL patents over the total number of patents in the sample. ${ }^{5}$ Table 1 shows the percentage of DL patents at three geographical levels, and the effect of the geographical unit of analysis on the probability of a patent being CL or DL. About $30 \%$ of total patents are DL. Moreover, by comparing the three regional units, the probability of DL does not change greatly. It goes from $31.6 \%$ for NUTS3, to $29.5 \%$ and $24.6 \%$ for the NUTS2 and NUTS1 regions. Correspondingly, the probability of CL goes from $75.4 \%$ for NUTS1, to $70.5 \%$ and $68.4 \%$ for the NUTS2 and NUTS3 regions. This is an interesting result per sé as it says that the vast majority of patents that are co-localised at the country level (i.e. inventors from the same country) are co-localised at the much more disaggregated provincial level as well. Put differently, this analysis shows that the network of inventors in a patent is typically composed of individuals located very close to one another (same city, same territorial area).

Table 1: DL and CL patents at the three regional levels.

\begin{tabular}{|l|l|l|l|}
\hline & DL patents & CL patents & Total number of patents \\
\hline
\end{tabular}

\footnotetext{
${ }^{4}$ The only restriction for the selection of the sample is that at least one inventor in each patent has to be localised in a European region. This is because we have only European regional data.

${ }^{5}$ We use the zip code in the address of the inventors to assign each inventor to his/her NUTS3, NUT2, and NUTS1 region. We chose the most disaggregated NUTS3 level because it better represents the size of a cluster where spillovers due to the geographical proximity can take place.
} 


\begin{tabular}{||c|c|c|c||}
\hline NUTS1 & 138 & 422 & 560 \\
& $24.6 \%$ & $75.4 \%$ & $100 \%$ \\
\hline NUTS2 & 165 & 395 & 560 \\
& $29.5 \%$ & $70.5 \%$ & $100 \%$ \\
\hline NUTS3 & 177 & 383 & 560 \\
& $31.6 \%$ & $68.4 \%$ & $100 \%$ \\
\hline
\end{tabular}

Source: Our elaboration from the EPO data.

The share of CL patents in Table 1 is also suggestive of the fact that the geographical proximity among inventors is important to pull them together. This proximity is either among inventors belonging to the same firm or among inventors located in the same small geographical area. In the case of CL patents, the effect of the firm and the cluster are blended together. Hence, Table 1 does not test our first proposition. To do so, we compare the characteristics of DL and CL patents. Specifically, we compute the mean number of inventors and the mean number of supplementary classes of CL and DL patents. We use these means as proxies for the "quality" of the coordination activity played by the firm (in the case of DL patents), and by the geographical proximity (in the case of CL patents).

Table 2: Characteristics of DL and CL patents.

\begin{tabular}{||l|c|c||}
\hline \hline & Mean number of inventors & Mean number of supplementary classes \\
\hline DL patents & 3.9 & 1.8 \\
\hline CL patents & 2.2 & 1.6 \\
\hline Total sample & 2.5 & 1.6 \\
\hline
\end{tabular}

Source: Our elaboration from the EPO data.

Table 2 shows that the networks of inventors that produce DL patents, and the complexity of these innovations are, on average, greater than those for the whole sample (and, clearly, for CL patents). This suggests that the coordination played by the firm is more effective than the coordination played by the geographical proximity among inventors.

The low share of DL patents in the sample, however, suggests that the vast majority of companies do not have internally the competencies to coordinate such collaborations across distances. To check whether large firms are better at producing DL patents, we distinguish between the "Fortune 500" and the "other" firms. Table 3 shows that the "Fortune 500" companies tend to produce a higher percentage of DL patents than the "other" firms. The share of DL patents over the total number of patents invented by the "Fortune 500" firms is $36.5 \%$, compared to $25.0 \%$ of DL patents produced by the "others". Moreover, patents 
assigned to these very large multinational companies are produced by a larger number of inventors (3.2 inventors on average) and are more interdisciplinary (2.4 supplementary classes on average) than patents produced by the "other" firms. On average, these are invented by networks composed of 2.3 inventors, and list 1.8 supplementary classes.

Table 3: Firms characteristics vs. patent characteristics.

\begin{tabular}{||l|c|c|c||}
\hline \hline & DL patents & Mean number of inventors & $\begin{array}{c}\text { Mean number of } \\
\text { supplementary classes }\end{array}$ \\
\hline "Fortune 500" & 106 & 3.2 & 2.4 \\
firms & $36.5 \%$ & 2.3 & 1.8 \\
\hline "Others" & $\begin{array}{c}56 \\
25.0 \%\end{array}$ & & \\
\hline
\end{tabular}

Source: Our elaboration from the EPO data.

Note: these data do not include universities, government and "individual" inventors.

Moreover, not only do very large companies coordinate larger networks of inventors to produce more interdisciplinary patents than the "others" but, when patents invented by the "Fortune 500" companies are DL, the networks of inventors becomes even larger. The average number of inventors listed in DL patents produced by the "Fortune 500" companies is 4.2. The number of supplementary classes is stable around 2 (not shown here). This suggests that large multinational companies draw on globally dispersed competencies and coordinate inventors across distances to produce interdisciplinary patents.

To sum up, the fact that also the "Fortune 500" companies tend to develop more CL patents compared to DL patents suggests that geographical proximity matters even for large multinational firms. They tend to develop innovations in specific regions or subsidiaries, pulling together competencies locally, at the regional level. But, the greater share of DL patents for the "Fortune 500" companies, and the higher average number of inventors and supplementary classes listed in their patents suggest that large internationalised companies may also act as global networks for the development of innovations. They can coordinate inventors localised in different places. Moreover, when this happens, the coordination played by the firm is more effective than the geographical proximity, as shown by the larger networks of inventors that take part in the project, and by the greater interdisciplinarity of the innovations. $^{6}$

\footnotetext{
${ }^{6}$ We repeated the elaborations by using other proxies for the size and the degree of multinationality of the firms - i.e. number of subsidiaries, total sales, number of employees, and R\&D expenditures. The results reflect those in Tables 1, 2, and 3.
} 


\subsection{The technological cluster and the networks of inventors.}

This section explores our second proposition. It examines whether the technological characteristics of the regions in which the inventors are localised affect the probability that the inventors collaborate, and the characteristics of the outcome patents. Our expectation is that the higher is the technological characteristics of a region, the more complex (interdisciplinary) are the patents produced, and the greater is the probability that the inventors are co-localised. The underlining argument is that in technology-intensive regions, where innovative activities agglomerate, it is easier to find the specialised and complementary competencies needed in complex R\&D projects. Moreover, since people with complementary expertise are located very close to one another, the probability to collaborate increases. We also expect this probability to be higher for smaller and less global firms. These firms might use the advantages of the technological cluster to compensate the lack of internal scientific competencies and coordination capabilities.

We begin by defining a technological cluster. The Eurostat Regio database (1995), the Eurostat database on patents (1997) and the European R\&D database (1996) provide information on regional characteristics such as the GDP, the extension of the geographical area, the number of employees in the manufacturing and service sectors, the population, the patents invented and applied in the regions in different sectors, and the number of chemical laboratories established by public and private institutions. After looking at the distribution of these variables across the European NUTS3 regions we decided that the number of chemical laboratories - both private and public - was a good proxy for the technological intensity and infrastructure developed by a region. As expected, other variables, such as the number of patents invented in each area, are correlated with the number of laboratories. As for the number of chemical laboratories, we also checked that the firms in our database do not determine themselves the characteristics of the cluster. We calculated the share of laboratories owned by our companies over the total number of laboratories in each region. The results show that these companies have only a small fraction of total R\&D laboratories in each region (not shown here).

We then defined a cluster according to the number of laboratories established in each region. The criterion for deciding the threshold between cluster and non-cluster areas is the following. 
The distribution of chemical laboratories in the European regions is very skewed. ${ }^{7}$ The total number of regions in which these 560 patents have been invented is 116 . The number of chemical laboratories localised in these regions ranges from 0 to 647. Interestingly, however, 103 out of 116 regions host less than 100 laboratories. Only the last decile of the European regions in our sample has between 100 and 647 chemical laboratories. We termed the regions in this decile as the technological clusters.

Table 4 shows that the probability of a patent being CL in the technological clusters is higher than in non-cluster regions. The probability of CL patents goes from $63.6 \%$ in non-cluster areas to $77.3 \%$ in the "clusters". The share of DL patents falls correspondingly.

Table 4: Cluster vs. non-cluster regions and patent characteristics.

\begin{tabular}{||l|c|c|c||}
\hline \hline & CL patents & Mean number of inventors & $\begin{array}{c}\text { Mean number of } \\
\text { supplementary classes }\end{array}$ \\
\hline Cluster & 153 & 2.7 & 1.9 \\
\hline Non-cluster & $77.3 \%$ & 2.9 & 1.5 \\
& $63.6 \%$ & & \\
\hline
\end{tabular}

Source: Our elaboration from the EPO data.

Table 4 also shows the mean number of inventors and the mean number of supplementary classes of patents invented in cluster and non-cluster regions. The results suggest that being in a cluster does not influence the level of interdisciplinarity of a patent and the breadth of the network of inventors. As we shall see in the next section, this is because the table does not highlight the net effect of being in a cluster over the interdisciplinarity and the breadth of the collaboration. To do so one needs to control for other factors. The multiple correlation analysis performed in section 6 aims at doing this.

The second proposition also argues that the cluster is a better coordination mechanism for firms that do not have the organisation capabilities and the scientific competencies needed to develop complex R\&D projects internally. Table 5 shows the percentage of patents performed in cluster and non cluster regions by "other" companies over the total number of patents performed in the two types of regions. It appears that the probability of a patent being produced by "others" increases from $40.2 \%$ in non-cluster areas to $49.0 \%$ in the clusters. The opposite pattern holds for the "Fortune 500" firms. This supports the idea that the

\footnotetext{
${ }^{7} \mathrm{We}$ are now considering the regions in which the 560 patents in our database have been invented.
} 
technological cluster is comparatively more attractive for smaller and less global firms compared to large multinational companies. Again, however, when we compute the average number of inventors and the average number of supplementary classes listed in the patents invented by the "other" firms in the clusters, and compare them to those invented in the noncluster regions, the results are inconclusive. The networks of inventors are slightly smaller in the clusters. The interdisciplinarity of the patents is a slightly higher for patents invented in the clusters. Again, section 6 will perform multiple correlations to control for other factors that might affect the level of interdisciplinarity and the number of inventors of the innovations.

Table 5: Technological clusters, firms' and patents' characteristics.

\begin{tabular}{||l|c|c|c|c|c||}
\hline \hline & $\begin{array}{c}\text { "Fortune } \\
500 " \text { firms }\end{array}$ & Others & Total* & $\begin{array}{c}\text { "Others": } \\
\text { Mean number of } \\
\text { inventors }\end{array}$ & $\begin{array}{c}\text { "Others": } \\
\text { Mean number of } \\
\text { suppl. classes }\end{array}$ \\
\hline Cluster & 101 & 97 & 198 & 2.3 & 1.5 \\
\hline Non-cluster & $51.0 \%$ & $49.0 \%$ & $100 \%$ & & 1.2 \\
& $59.8 \%$ & $40.2 \%$ & $100 \%$ & 2.9 & \\
\hline
\end{tabular}

Source: Our elaboration from the EPO data.

Note: this is the total number of patents in cluster and non-cluster regions respectively. The data do not include universities, government and "individual" inventors.

These two tables show that there is a correlation between the "technological" characteristics of the regions, the probability of the networks of inventors being located in the same area, and the probability of the patents being invented by smaller companies.

A final question concerns the importance of being in a cluster for large internationalised companies compared to the "others" in order to produced CL patents. Table 3 shows that the "Fortune 500" companies tend to produce a higher percentage of DL patents compared to the "other" firms. However, also for the "Fortune 500" companies the share of CL patents is $63.5 \%$ over the total number of patents that they got assigned. The question is: where are these CL patents localised? Put differently, is there an effect of the cluster over the probability that large multinational companies co-localise the network of inventors for producing a patent? Table 6 shows that the percentage of CL patents produced by the "Fortune 500" firms increases from $57.7 \%$ to $74.3 \%$ when moving from a non-cluster to a cluster region. Therefore, also for the largest chemical companies, the probability of a patent being CL is higher in the clusters. Clearly, the share of CL patents is higher for small firms, and it increases for both large and small companies, as the regions become more technology- 
intensive. But the increase is more marked for large internationalised firms than for the smaller firms. The share of CL patents produced by large companies increases by $16.6 \%$ when companies move to the clusters. The increase in the share of CL patents of smaller firms is less pronounced $(6.6 \%)$.

Table 6: Technological clusters. "Fortune 500" firms vs. "Others".

\begin{tabular}{||l|c|c||}
\hline \hline & $\begin{array}{c}\text { "Fortune 500" firms: } \\
\text { Share of CL patents over the total number } \\
\text { of multinational patents. }\end{array}$ & $\begin{array}{c}\text { Share of CL patents over } \\
\text { of "others" patents. }\end{array}$ \\
\hline Cluster & $74.3 \%$ & $80.4 \%$ \\
\hline Non-cluster & $57.7 \%$ & $72.4 \%$ \\
\hline
\end{tabular}

Source: Our elaboration from the EPO data.

Note: these data do not include universities, government and "individual" inventors.

This suggests that although the "Fortune 500" firms are better mechanisms to coordinate competencies and researchers localised in different firms' units and geographical areas, being in a technological cluster might be beneficial for pulling together localised competencies for the large firms as well.

\section{Multiple correlations: Poisson and Negative Binomial regressions.}

The tables presented in Section 4 show that both the large multinational firm and the technological cluster are effective mechanisms for coordinating the networks of inventors. Some results, however, are inconclusive. This is because the statistics presented in the tables could not isolate the effect of the independent variables over the probability of a patent having certain characteristics. To do so, this section performs some multiple correlation exercises by means of Poisson and Negative Binomial models. The purpose of these regressions is to describe the effect of regional and firms' characteristics over the number of inventors that invented a patent, and the probability of a patent being interdisciplinary.

The models are specified as follows. The total sample is composed of 560 European patents $(\mathrm{i}=1, \ldots . ., 560)$. We run two regressions. The dependent variable of the first regression is the number of inventors that take part in the development of a patent (NRINV). The dependent variable of the second regression is the degree of interdisciplinarity of a patent, given by the number of supplementary classes that are listed in the patent document (NRCL). The independent variables are regional and firms' characteristics. Hence: 
$\mathrm{NRINV}_{\mathrm{i}}=\beta_{0}+\beta_{1} \cdot \mathrm{LABS}_{\mathrm{i}}+\beta_{2} \cdot \mathrm{BR}_{\mathrm{i}}+\beta_{3} \cdot \mathrm{GDP}_{\mathrm{i}}+\beta_{4} \cdot \mathrm{MNE}_{\mathrm{i}}+\beta_{5} \cdot \mathrm{NRASS}_{\mathrm{i}}+\beta_{6} \cdot \mathrm{AREA}_{\mathrm{i}}+$ $\beta_{7} \cdot \mathrm{POP}+\mathrm{u}_{\mathrm{i}}$

The same applies for the second regression where $\mathrm{NRCL}_{\mathrm{i}}$ is the dependent variable. The independent variables are:

- LABS - The number of laboratories performing chemical research in the NUTS3 region where the patent has been invented. We expect the number of laboratories to have a positive impact on the patent's interdisciplinarity, and on the breadth of the network of inventors. A rich external environment should offer a wide range of opportunities to find specialised and complementary competencies.

- BR - The number of patents in all sectors invented in the NUTS3 region where the patent has been invented. This is used as a proxy for the general technological intensity of a region. We expect the interdisciplinary of a patent and the breadth of the network of inventors being positively influenced by a technologically conducive external environment.

- GDP - The Gross Domestic Product per capita. The GDP per capita is suggestive of the extent of richness and economic development of a region.

- POP and AREA - The population and the area (squared kilometres) of the regions are used as control variables for the size of the regions.

- MNE - This is a dummy that takes the value 1 when the assignee is a "Fortune 500" firm. We expect this characteristic to have a positive impact on the interdisciplinary and on the number of inventors listed in a patent.

- NRASS - The number of assignees that collaborate to develop a patent. This is supposed to have a positive impact on the number of inventors that cooperate to invent a patent, and on the degree of interdisciplinarity of the patent. Clearly multiple assignees are likely to arise from formal collaborations, like $R \& D$ joint-ventures or other agreements. And these firms collaborate to pull together complementary or interdisciplinary competencies, or scale. Hence, this variable is likely to affect the number of inventors or the multidisciplinarity of the patent.

All these variables are expressed in logs. The results of the econometric estimates are shown in Table 7. 
Table 7: Estimates of the Poisson and Negative Binomial regressions.

\begin{tabular}{|c|c|c|c|c|c|}
\hline & & \multicolumn{2}{|c|}{$\begin{array}{c}\text { Dependent variable: number of } \\
\text { inventors }(\text { NRINV) }\end{array}$} & \multicolumn{2}{|c|}{$\begin{array}{l}\text { Dependent variable: number of } \\
\text { supplementary classes (NRCL) }\end{array}$} \\
\hline & & Poisson & $\begin{array}{l}\text { Negative } \\
\text { Binomial }\end{array}$ & Poisson & $\begin{array}{l}\text { Negative } \\
\text { Binomial }\end{array}$ \\
\hline$\beta_{0}$ & Constant & $\begin{array}{c}1.18 \\
(0.82) \\
\end{array}$ & $\begin{array}{c}2.35 \\
(0.87) \\
\end{array}$ & $\begin{array}{l}-1.51 \\
(1.16) \\
\end{array}$ & $\begin{array}{c}0.21 \\
(1.14) \\
\end{array}$ \\
\hline$\beta_{1}$ & LABS & $\begin{array}{c}0.13 \\
(0.06) \\
\end{array}$ & $\begin{array}{c}0.14 \\
(0.06) \\
\end{array}$ & $\begin{array}{c}0.15 \\
(0.08) \\
\end{array}$ & $\begin{array}{c}0.11 \\
(0.07) \\
\end{array}$ \\
\hline$\beta_{2}$ & $\mathrm{BR}$ & $\begin{array}{c}0.02 \\
(0.06)\end{array}$ & $\begin{array}{c}0.02 \\
(0.06) \\
\end{array}$ & $\begin{array}{l}-0.03 \\
(0.06) \\
\end{array}$ & $\begin{array}{l}-0.01 \\
(0.06) \\
\end{array}$ \\
\hline$\beta_{3}$ & GDP & $\begin{array}{l}-0.05 \\
(0.11) \\
\end{array}$ & $\begin{array}{l}-0.03 \\
(0.11) \\
\end{array}$ & $\begin{array}{c}0.21 \\
(0.15) \\
\end{array}$ & $\begin{array}{c}0.07 \\
(0.15) \\
\end{array}$ \\
\hline$\beta_{4}$ & MNE & $\begin{array}{c}0.40 \\
(0.10) \\
\end{array}$ & $\begin{array}{c}0.40 \\
(0.09) \\
\end{array}$ & $\begin{array}{c}0.30 \\
(0.10) \\
\end{array}$ & $\begin{array}{c}0.26 \\
(0.10) \\
\end{array}$ \\
\hline$\beta_{5}$ & NRASS & $\begin{array}{c}0.48 \\
(0.14) \\
\end{array}$ & $\begin{array}{c}0.50 \\
(0.14) \\
\end{array}$ & $\begin{array}{l}-0.06 \\
(0.25) \\
\end{array}$ & $\begin{array}{l}-0.06 \\
(0.24) \\
\end{array}$ \\
\hline$\beta_{6}$ & AREA & $\begin{array}{l}-0.02 \\
(0.07)\end{array}$ & $\begin{array}{l}-0.02 \\
(0.07)\end{array}$ & $\begin{array}{l}-0.16 \\
(0.07)\end{array}$ & $\begin{array}{l}-0.11 \\
(0.06) \\
\end{array}$ \\
\hline$\beta_{7}$ & POP & $\begin{array}{l}-0.12 \\
(0.07) \\
\end{array}$ & $\begin{array}{l}-0.13 \\
(0.07) \\
\end{array}$ & $\begin{array}{c}0.23 \\
(0.07) \\
\end{array}$ & $\begin{array}{c}0.19 \\
(0.07) \\
\end{array}$ \\
\hline & Delta & & $\begin{array}{c}3.58 \\
(1.32) \\
\end{array}$ & & $\begin{array}{c}1.90 \\
(0.46) \\
\end{array}$ \\
\hline Num & of observations & 402 & 402 & 402 & 402 \\
\hline & -likelihood & -696.335 & -689.750 & -708.420 & -686.333 \\
\hline
\end{tabular}

Source: Elaboration from the EPO data, and EUROSTAT

Note: Heteroskedastic consistent standard errors in parentheses (Eicker-White).

As far as the breadth of the network of inventors is concerned (first two columns on the left), the technological intensity of a region proxied by the number of chemical laboratories, positively influences the number of inventors that take part in an innovation. The coefficient of LABS is positive and significant. By contrast, the general technological environment proxied by the number of patents invented in all sectors in each region - does not affect the probability of collaboration among inventors in the chemical industry. This suggests that changes in the scientific and technological environment in the chemical sector affect the probability of having larger collaborations. But changes in the general technological environment seem to play no role in affecting the breadth of such collaborations. This holds also when controlling for other regional characteristics. The estimated coefficients of the control variables - GDP, POP and AREA - are not significant.

As for firms' characteristics, the results confirm the patterns highlighted in section 5.1. Being large and multinational positively affects the probability of a patent being invented by a large number of inventors. The estimated coefficient of MNE is positive and significant. This 
suggests that larger firms have the competencies and the internal organisation to coordinate and pull together a larger number of inventors. This also suggests that the advantages of the technological cluster in coordinating the networks of inventors may be highly beneficial to smaller companies compared to larger and more global ones - i.e. the "Fortune 500" firms. Also the number of firms to which the patent is assigned is positively correlated with the breadth of the network of inventors. The estimated coefficient of NRASS is positive and significant.

As expected, the estimates of the second regression with the number of supplementary classes as the dependent variable confirm the results achieved for NRINV (last two columns on the right). Large firms still play an important role over the level of interdisciplinarity of the patents. This confirms the intuition of the company being an efficient means for coordinating internally developed competencies. Also the effect of the cluster holds but it is less significant. The next section will discuss these results.

\section{Discussion: organisations or "markets"?}

Networks among individuals are a common practice in R\&D work. Only about one-fourth of our universe of chemical patents feature one inventor. All other patents feature two or more inventors, and a good fraction is made by 4 or more inventors. Moreover, patents with a larger number of inventors tend to be more complex and interdisciplinary, as shown by the positive correlation between the number of inventors and the number of supplementary technological classes assigned to the patent. In other words, more inventors seem to be necessary in order to produce innovations that relate to more technological classes and disciplines.

This paper explored whether geographical proximity or the affiliation to the same firm matters for fostering the collaboration among inventors. Put differently, this is a way to asking whether the organisation or the geographical cluster are two alternative "coordination modes" for encouraging formalised knowledge spillovers to arise. Our conclusion is that both "coordination modes" need to be qualified in order to affect the networks of inventors. In fact, neither the affiliation to the same organisation, nor the geographical proximity per sé seem to really matter for better coordinate the networks of inventors. Rather, the geographical proximity is helpful when inventors are localised in a technology-intensive region - i.e. the technological cluster. The affiliation to the same firm matters when the firm is large and 
multinational. In these cases, both geographical proximity and the firm are effective vehicles for inducing collaborations among inventors. They also affect the characteristics of the innovations, as shown by the higher level of interdisciplinarity of the patents, and the larger number of inventors that collaborate.

As far as the firm is concerned, the share of DL patents produced by large chemical multinationals is greater than the share of DL patents produced by the "other" firms. The number of inventors and the level of interdisciplinary of the DL patents invented by the "Fortune 500" companies are greater than for the "other" firms. This suggests large multinational companies can better act as "global networks" for R\&D compared to smaller companies. Moreover, when they draw on globally dispersed competencies and coordinate inventors localised in different regions and research units, they produce more complex patents. This might be because very large multinational companies have better internal capabilities to coordinate de-localised competencies compared to smaller and less global firms. When they produce patents by drawing on these dispersed competencies, they seem to be a more effective coordination mechanism than the geographical proximity among inventors - i.e. the DL patents produced by the "Fortune 500" companies are "qualitatively" better.

However, the large share of CL patents suggests that only a few firms have the capabilities to coordinate R\&D projects across distances. Moreover, when the organisation lacks the coordination competencies needed to act as a "global network", geographical proximity becomes extremely important to induce people collaborate. Being close to one another seems to reduce the cost of coordination among inventors. The data shows that $75 \%$ of patents produced by the "other" firms are CL. This share is $63.5 \%$ for large multinational firms - the "Fortune 500" firms. These large percentages indicate that inventors involved in the same $\mathrm{R} \& \mathrm{D}$ project tend to be locally close to one another. These patterns rise two important issues.

First, the fact that also the "Fortune 500" firms perform a large share CL patents over their total patenting activity, rises questions concerning the R\&D strategies of multinational companies. There are quite a few empirical studies on the globalisation of research, but the results are controversial. Some of them show that there is a pattern towards the location of research on global basis, and that large internationalised firms are increasingly organising research activities as they were global innovation networks (see, for example, Cantwell, 
1991). By contrast, other authors emphasise the non-global nature of innovative activities (see, for example, Patel and Pavitt, 1990).

Our results suggest that the latter view prevails, and that the vast majority of large multinational companies might not behave as most studies suggest. Only a few of these large multinational companies act as networks that harness the needed expertise in different and distant places, and link them together through internal coordination mechanisms. By contrast, most of them tend to develop "locally bounded" innovations. At least during the process of developing innovations, they tend to carry out research projects by relying on very colocalised competencies. This suggests that the organisation of $R \& D$ activity within multinational companies tends to be very well defined at the level of the subsidiary. These firms tend to create subsidiaries that are the locus of several specialised and complementary competencies for innovation, and the process of developing innovations takes place at this level.

Second, another important question concerns the comparative advantage of being in a technological cluster for smaller firms compared to large multinationals. The technological cluster, like the large company, typically features a good deal of different and complementary competencies inside the territorial area. Therefore, firms localised in a technological cluster have limited need for finding these competencies outside the region. But, who benefits more from being in such a conducive environment? The results of this paper suggest that colocalisation is comparatively more important for the "other" firms. Hence, although both small and large firms take advantage from being in a technological cluster, smaller companies tend to rely on the external scientific and technological environment more heavily than large multinationals. Geographical proximity in a technological intensive region plays a more important coordination function for companies that lack the internal scientific competencies and the organisation capabilities needed to coordinate the collaborations. In this sense, proximity is a good substitute for the organisation.

Finally, the results of this paper show that knowledge spillovers might not be "tacit" elements freely available in the atmosphere. Rather, they depend on specific actions of economic agents, like the setting up of a firm, or the localisation in a technological intensive cluster. This has important implications for corporate strategy and technology policy. If potential 
beneficiaries cannot take advantage of spillovers unless they undertake specific complementary investments, technology policy should conceive interventions aimed at facilitating their absorption and the rise of externalities and increasing returns that are naturally associated with spillovers.

\section{Conclusions}

This paper aimed at performing a micro-level analysis of the networks in the chemical industry. Some authors have addressed some of these issues. Most of them have explored the collaboration among scientists to produce co-authored journal articles. This paper analyses the technological side of R\&D collaborations. The main question that the paper explores is: how important is geographical proximity compared to the affiliation to the same organisation to induce the collaboration among different inventors? To answer this question, the paper examines several characteristics of the European chemical patents, the regions where the inventors of the patents are located, and the firms to which the patents are assigned.

The first part of the paper is based on the examination of the full population of European chemical patents between 1986-1997 (201,536 patents). The results show that co-patenting is a rare event in European chemicals. While this may be related to the peculiarities of this industry (typically composed of some very large firms), it was nonetheless surprising to see that less than $10 \%$ of the European chemical patents involve more than one assignee. This suggests that, while research collaborations are an important phenomenon, it should not be overestimated. The vast majority of patents are assigned to one institution, which then assumes the property rights on that invention. Put differently, there seems to be little networking among firms or between firms and other institutions when actual rights on the inventions are concerned. There are also important inter-country differences in this pattern. Thus, for instance, countries like the UK or the Netherlands feature respectively about $20 \%$ and $27 \%$ of patents with multiple assignees. It is interesting to compare these cases with the leading chemical producing country in Europe, Germany. Germany features only slightly more than $6 \%$ of co-patents, below the European average. This is suggestive of the importance of in-house research for producing innovations in German chemicals compared to the higher openness of UK chemical innovators. 
Unlike co-patenting, networks appear to be more important when looking at the collaborations among the individuals producing the patents. About $75 \%$ of our universe of chemical patents feature two or more inventors. The paper examined the characteristics of these collaborations, and the coordination mechanisms - the firm vs. the geographical proximity among inventors that pull people together with the aim of producing an innovation. To do so the paper used the addresses of the individual inventors for a random sample of 560 of these patents at the most disaggregated territorial level (NUTS3 European regions). Data were collected about the assignees and the NUTS3 regions of the inventors.

Our findings suggest that being part of a large multinational firm and of a technological cluster affects the probability of collaboration among the inventors. One possible interpretation of these results is that both the large firm and the technological cluster are effective "co-ordination modes" for organising knowledge spillovers. The regressions enabled us to better understand the interdependence among the variables and their effects. We run two regressions. The first one examined the relation between the number of inventors listed in a patent, and the characteristics of the firm and the region in which it was invented. The second one explored the relation between the degree of interdisciplinary of a patent and the same regional and firm characteristics. The results confirm that both large companies and the technological clusters are good at coordinating the networks of inventors.

\section{Appendix: Data description}

The data used in this paper are drawn from various sources. First, from the European Patent Office (EPO, 1998), we extracted a database of 201,531 chemical patents granted and applied between 1986-1997.

From all the information available in the front page of a patent document we collected the following details on each chemical patent: the number, names and addresses of the assignees; the number, name and addresses of the inventors; the obligatory IPC class, and the number and type of supplementary IPC classes; the date of the patent application. We did not make any distinction between patent applications that have been granted, and those that have not been granted (yet). 
The first step of the preparation of the patent data was to locate the invention geographically. For all the 201,531 patents, the address of the inventor was used to assign each inventor to a specific country. Each patent was then defined as CL or DL at the country level. The number of assignees, the number of inventors, and the number of supplementary classes were also calculated, so to define the breadth of the networks of assignees and inventors, and the level of interdisciplinary of the patents.

The second step was to select a random sample of 560 innovations from these 201,531 patents. By using the information on the zip code contained in the addresses, we assigned each inventor to a specific NUTS3, NUT2, and NUT1 region, and decided whether a patent was CL or DL at the regional level. Again, the number of assignees, the number of inventors, and the number of supplementary classes were calculated.

The names of the applicants of these 560 patents were standardised in order to merge mother and daughter firms under the same name. The Who Owns Whom (1995) database was used to investigate these mother-daughter relations. The Who Owns Whom and Compustat (1995) databases were also used to collect firm-level information (about the assignee), such as the number of subsidiaries owned by the assignee, the sales, the R\&D expenditures, and the number of employees. Fortune 500 (1995) was used to select the firms that we termed "Fortune 500".

We also collected information about the NUTS3 regions in which the inventors were located. ${ }^{8}$ From the EUROSTAT REGIO database (1995) we collected information about the economic characteristics of these regions, such as the GDP, the number of employees in the manufacturing and service sectors, and the population. The Eurostat database (1997) on patents was used to calculate the number of patents invented in each region, and filed at the EPO in 1986-1990. This was used as a proxy for the innovative activity in the area. Finally, we downloaded some 9,000 chemical laboratories from the European $R \& D$ database, published by Reed Elsevier Publisher, 1996. The laboratories were classified as private labs if

\footnotetext{
${ }^{8}$ When the inventors were CL, the NUTS3 region where the patent was invented was obviously the region were all the inventors were located. When the inventors were DL, we considered the region where more than $50 \%$ of the inventors were located. In the few cases in which this $50 \%$ was not reached, we used the region of the first inventor listed in the patent.
} 
they were firms' laboratories, or public labs if they were government research institutions, universities, and hospitals. They were also assigned to their specific NUTS3 regions.

Acknowledgements: This paper is part of a broad project whose title is "Networks and industrial dynamics " coordinated by Professor Franco Malerba. This project has been funded by the Italian Minister of University and Scientific Research.

\section{Main references:}

Audretsch, D.B., and Feldman M.P., 1994, "Knowledge Spillovers and the Geography of Innovation and Production", American Economic Review, Vol.86 (3), pp.630-640.

Cantwell J. "The international agglomeration of R\&D”, 1991 in Global Research Strategy and International Competitiveness, Casson M., 1991

Coe, D.T., and Helpman, E., 1995, "International R\&D Spillovers", European Economic Review, Vol. 39, pp. 859-887.

de Solla Price D.J. and Beaver D.B., 1966, "Collaboration in an invisible college", American Psychologist 21 (1), 1011-1018.

Freeman, C., 1991 "Networks of innovators: a synthesis of research issues", Research Policy

Griliches Z., 1990 "Patent statistics as economic indicators: a survey" Journal of Economic Literature.

Hagedoorn J., and Schakenraad J, 1990, Strategic partnering and technological cooperation, in Freeman C. and Soete L. (eds.) New Explorations in the Economics of Technical Change, Pinter, London.

Jaffe, A., 1986, "Technological Opportunity and Spillovers of R\&D: Evidence from Firms' Patents, Profits and Market Value", American Economic Review 76(5), 984-1001.

Jaffe, A., Trajtenberg, M., and Henderson, R., 1993, "Geographic Localization of Knowledge Spillovers as Evidenced by Patent Citations", Quarterly Journal of Economics, Vol.63 (3), pp.577-598.

Lamoreaux, N., and Sokoloff, K., 1997, "Location and Technological Change in the American Glass Industry during the Late Nineteenth and Early Twentieth Centuries", NBER WP 5938, NBER, Cambridge MA.

Lamoreaux, N., and Sokoloff, K., 1998, "Inventors, Firms, and the Market for Technology: US Manufacturing in the Late Nineteenth and Early Twentieth Centuries", in Lamoreaux, N., Raff, D., and Temin, P., (eds.), Learning by Firms, Organizations, and Nations, forthcoming.

Melin G. 1999, "Pragmatism and self-organization. Research collaboration on the individual level", Research Policy.

Merton R.K., 1973, The sociology of science, The University of Chicago Press, Chicago. 
Narin F. and Withlow E.S., 1990, "Measurement of scientific cooperation and coauthorship in CEC-related areas of science" Vol. 1 Commission of the European Communities (EUR 12900 EN), Brussels.

Patel P. and Pavitt K., 1990, Large Firms in the Production of the World's Technology: An Important Case of Non-Globalisation, Journal of International Business Studies, 22 (1) 1-21

Scherer F.M., 1983 "The propensity to patent" International Journal of Industrial Organisation.

Swann P., Prevezer M. and Stout D., 1998, (eds.) The Dynamics of Industrial Clustering, Oxford University Press.

Zucker, L., Darby, M., and Armstrong, J., 1998, "Geographically localized knowledge: Spillovers or markets?", Economic Inquiry 36, January, 65-86. 